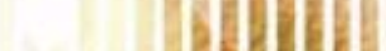

1

1

.

西

\section{Control of the Active Suspension for In-Wheel Motor*}

\author{
Ying MA**, Zhaoxiang DENG** and Dan XIE** \\ ** The State Key Laboratory of Mechanical Transmission, Chongqing University \\ No.174, Shazheng street, Shapingba District, Chongqing City, P.R. China, 400030 \\ E-mail: zxdeng@cqu.edu.cn
}

\begin{abstract}
This study raises a new electric wheel with active control of suspension for in-wheel motor. Proceeding from the reality, we made a simulation analysis on these four models: a sample car with no motor, a motor with fixed joint, and active/inactive control suspension for in-wheel motor. During the analysis, less-than-10mm relative vertical displacement was used as a prerequisite, reducing the car's acceleration, the suspension flexivety, and the wheel's load as basic conditions, reducing the wheel's vertical acceleration as the primary target, LQR control of active suspension as the motive. According to the analysis, by optimizing the parameter of inactive control suspension for in-wheel motor, we can solve the vertical problems caused by the electric wheel's mass, but the vertical impact to in-wheel motor is still heavy. However, using active control suspension for in-wheel motor can not only rise the smoothness and safety of the car, but also reduce $64 \%$ of the vertical impact comparing to inactive control suspension. This improves the active control suspension for in-wheel motor can effectively resolve the electric cars' vertical problems both theoretically and practically.
\end{abstract}

Key words: Automobile, Design, Mass Transfer, Optimum Control, Simulation

\section{Introduction}

In-wheel motor driven electric car has excellent kinetic controlling performance, it can control the wheel's torque or speed, and very convenient for flat vehicle frame design and body-modeling design because of its' effective space utilization ${ }^{(1)}$ At present, researches on controlling system of electric car are mostly about controlling the yaw rate and the drafting-force. Controlling the yaw rate is achieved by controlling the driving motor ${ }^{(2)-(4)}$; controlling the drafting-force can generate motor torque that controlling the wheel's slip rate during acceleration, thus ensure the full control to the $\operatorname{car}^{(5)-(7)}$. However, in response to the energy conservation and reduction of pollutant policy, a electric car's curb weight is about $1000 \mathrm{~kg}$. To meet the car's dynamic property, each in-wheel motor weights about $30-52 \mathrm{~kg}$. If the in-wheel motor is fixedly joint to the wheel, the unsprung mass will increase, thus reducing the mass rate of body/wheel ${ }^{(8)-(10)}$. As a result, the indicators of the car's smoothness will be decreased in the range of high frequency resonate, especially, the wheel's dynamic load change will be obvious ${ }^{(11)}$. While the absolute value of the dynamic load of the wheel equals to 1, the dynamic load and the dead load of the wheel acting on the ground are of the same value, but with opposite directions, and the vertical load acting on the ground is 0 . At this moment, the wheel will skip off the ground, losing the vertical and side adhesion force, making the driving dangerous. To avoid this, we need to reduce the wheel's relative load while applying the in-wheel motor drive. In the event that the in-wheel motor fixedly joint to the wheel, the dynamic load of the wheel will increase, causing
${ }^{*}$ Received 16 Jan., 2013 (No. 13-0014) [DOI: 10.1299/jamdsm.7.535]

Copyright () 2013 by JSME 
vertical vibration to the wheel, leading to the bearing stressing hard, the inverting worsen, even causing the ring fire or parts damaged.

Vehicle's suspension affects the driving smoothness and controlling stability. Suspension system's main function is to pass the force and torque between wheels and the frame (or body), decreasing the shock caused by rough road, assuring driving smoothness and satisfaction. Since the sixth generation of last century, researches on active and has been carried out ${ }^{(12)-(14)}$. In order to reduce the negative affects caused by in-wheel motor's mass to vehicle's smoothness and safety, an article ${ }^{(15)}$ proves that applying spring and damper passive suspension between in-wheel motor and wheel can increase the auto's comfort properties. In the article ${ }^{(16)}$, they used the minimum vertical vibration of unsprung mass as target function, optimized the spring stiffness and damping parameter of dynamic damping mechanism. However, their report didn't mention in-wheel motor's relative vertical displacement to the wheel, nor the vertical vibration on the in-wheel motor.

Limited by existing wheel and motor's size, in-wheel motor's skipping range in the wheel is no more than $10 \mathrm{~mm}$. As different roads act differently upon in-wheel motors, this study focuses mainly on inear motion actuator fixed to the wheel, which is called active suspension system. Based on this system, we built an 1/4 sized model of the in-wheel motor driven mobile according to the suspension property parameters of the sample car, with inactive control suspension of in-wheel motor that was parameter optimized. In this study, we analyzed the effectiveness of active control suspension system of in-wheel motor on increasing the vehicle's smoothness and reducing the in-wheel motor's vibration on rough roads.

\section{Building active vibration isolation system model of in-wheel motor}

For the purpose of wheel and in-wheel motor with the active control suspension could have vertical relative movement while they rotate with the same angular velocity, we can apply flexible connection mechanism between the in-wheel motor's rotor and the wheel's spoke, spring and oscillating damper between the in-wheel motor's stator and the wheel's shaft. In this way, the in-wheel motor can move vertically relatively to the wheel and the body, while passing the driving force smoothly to the wheel. This method has been applied as a patent of invention, under the name 'in-wheel motor with high stability', 201210171175.X. To further increase vehicle's vertical performance and reduce the motor vibration, apply an active vibration isolation system between in-wheel motor's stator and wheel shaft, as shown in the figure 1(a). This system works mainly through the inear motion actuator 11. Structure of this kind can transform the mass of in-wheel motor and braking system to unsprung weight, and act as dynamic vibration absorber.

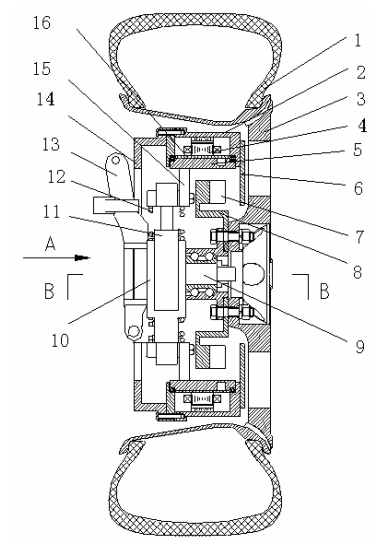

(a) Vertical section

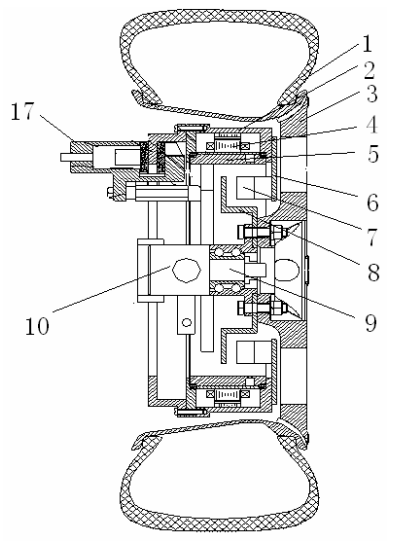

(b) Rotating 90 degrees

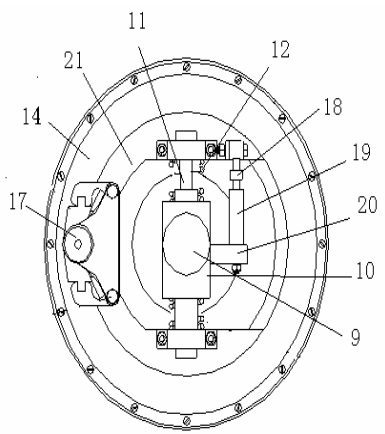

(c) Left view

Fig. 1 Active vibration isolation system design of the electric vehicles with in-wheel motor

In the figure $1(\mathrm{a}, \mathrm{b}, \mathrm{c}), 1$ refers to the tire, 2 rotor, 3 spoke, 4 stator, 5 stator shell (with water passage), 6 active part of the shaft joint (joint with the motor), 7 transforming part of the shaft joint (joint with the motor) , 8 driven part of the shaft joint (joint with the flange), 9 the shaft, 10 liner motor sleeve, 11 liner motor, 12 in-wheel motor spring, 13 steering 
knuckle, 14 brake disc, 15 connecting part between the stator and the liner motor, 16 stator loop in-wheel motor, 17 braking caliper, 18 damper stopper, 19 in-wheel motor damper, 20 mounting frame of the damper, 21 connecting part.

Process of passing the driving force: the rotor $2 \rightarrow$ driving plate $6 \rightarrow$ transforming plate $7 \rightarrow$ driven plate $8 \rightarrow$ spoke 3 。

Process of passing the braking force : braking caliper $17 \rightarrow$ braking plate $\rightarrow$ rotor $2 \rightarrow$ driving plate $6 \rightarrow$ transforming plate $7 \rightarrow$ driven plate $8 \rightarrow$ spoke 3 .

Process of passing the vertical force : ground $\rightarrow$ tire $1 \rightarrow$ spoke $3 \rightarrow$ shaft $9 \rightarrow$ liner motor sleeve $10 \rightarrow$ liner motor $11 \rightarrow$ connecting part between the stator and the liner motor $15 \rightarrow$ stator $4 \rightarrow$ rotor $2 \rightarrow$ active part of the shaft joint (joint with the motor) 6 .

Before the electric wheel was mounted, the $1 / 4$ sized vehicle's vertical vibration model is the ordinary dual-degree of freedom ${ }^{(11)}$. $1 / 4$ sized vehicle's vibration model with the in-wheel motor fixed joint to the wheel is shown in the figure 2(a). The 1/4 sized vehicle's vibration model with the in-wheel motor inactively suspended in the wheel as in our patent is shown in the figure 2(b). The 1/4 sized vehicle's vibration model with the in-wheel motor inactively suspended in the wheel as in our patent is shown in the figure 2(c).

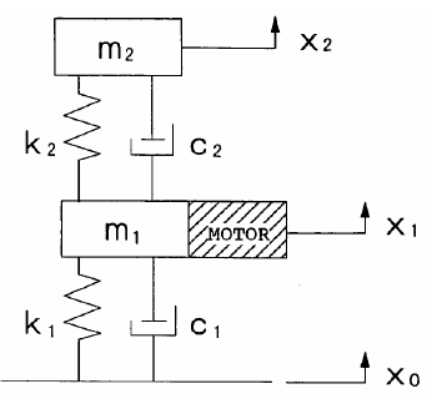

(a) Fixed joint in-wheel motor model

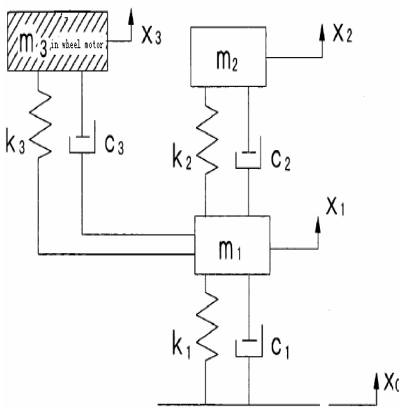

(b) Inactive control

suspension of in-wheel motor

model

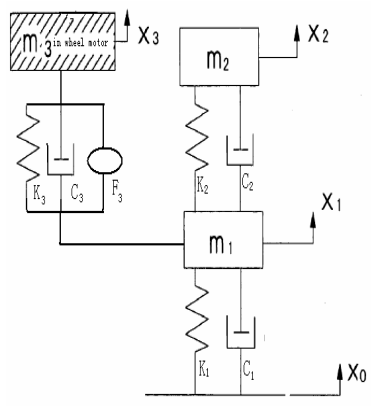

(c) Active control suspension of in-wheel motor model

Fig. 2 Electric wheel of different vehicle suspension configuration model

Table 1 1/4 sized of vehicle model parameters

\begin{tabular}{cc}
\hline Basic parameters & values \\
\hline 1/4 of the suspension mass m2 & $270 \mathrm{~kg}$ \\
Unsprung mass m1 & $32.5 \mathrm{~kg}$ \\
Mass of in-wheel motor m3 & $62 \mathrm{~kg}$ \\
Vehicle Suspension stiffness K2 & $22000 \mathrm{~N} / \mathrm{m}$ \\
Vehicle suspension damping C2 & $1218 \mathrm{Ns} / \mathrm{m}$ \\
In-wheel motor suspension stiffness K3 & $72591 \mathrm{~N} / \mathrm{m}$ \\
In-wheel motor suspension damping C3 & $3019 \mathrm{Ns} / \mathrm{m}$ \\
Tire vertical stiffness K1 & $220000 \mathrm{~N} / \mathrm{m}$ \\
Tire damping C1 & $50 \mathrm{Ns} / \mathrm{m}$ \\
Liner motor force $\mathrm{F}_{3}$ & $-1500 \mathrm{~N}$ \\
\end{tabular}

Differential equation of $1 / 4$ sized model with in-wheel motor actively suspended in the wheel

$$
\begin{aligned}
& m_{3} \dot{x}_{3}+K_{3}\left(x_{3}-x_{1}\right)+C_{3}\left(\dot{x}_{3}-\dot{x}_{1}\right)+F_{3}=0 \\
& m_{2} \ddot{x}_{2}+K_{2}\left(x_{2}-x_{1}\right)+C_{2}\left(\dot{x}_{2}-\dot{x}_{1}\right)=0
\end{aligned}
$$




$$
\begin{aligned}
& m_{1} \ddot{x}_{1}+K_{3}\left(x_{1}-x_{3}\right)+C_{3}\left(\dot{x}_{1}-\dot{x}_{3}\right)+K_{2}\left(x_{1}-x_{2}\right)+C_{2} \\
& \left(\dot{x}_{1}-\dot{x}_{2}\right)+K_{1}\left(x_{1}-x_{0}\right)+C_{1}\left(\dot{x}_{1}-\dot{x}_{0}\right)-F_{3}=0
\end{aligned}
$$

\section{Control of active suspension for in-wheel motor design}

So far, researches about in-wheel motor car were all based on a particular model, this brought a lot of difficulties to redesign the vehicle's suspension. For the commonality of mounting the in-wheel motor, one principle is not to change the vehicle's suspension structure. By applying a suspension system between in-wheel motor and wheel, transform the in-wheel motor's driving system to unsprung mass, while working as a dynamic vibration absorber.

Optimizing the control system of active suspension for in-wheel motor is aim to further increase the vehicle smoothness and stability, and reduce sharply the vertical vibration to the in-wheel motor (comparing to inactive suspension for in-wheel motor). And then, in-wheel motor can work in a more stable environment, with high performance and stability. This optimization limited on the relative vertical movement of in-wheel motor for the wheel. Physically, it means the relative vertical displacement of in-wheel motor and the wheel is no more than $10 \mathrm{~mm}$. This will decrease vehicle's vertical vibration acceleration as much as possible, limit the suspension travel route, avoid shocks to the bumper block by the suspension, the absolute value of the wheel's relatively dynamic load is less than 1 . In this situation, the vehicle will not skip off the ground. Decreasing vehicle's vertical vibration acceleration as much as possible would reduce the effects to in-wheel motor's performance caused by the vertical vibration.

According to LQG control theory ${ }^{(17)}$, the differential equation of active suspension system is transformed to the metric form, shown as:

$$
\dot{X}=A X+B U+D W
$$

In the formula: $X$ refers to the system status variable, $U$ refers to the active suspension control force, while $\mathrm{W}$ refers to the disturbing signal outside.

$$
\begin{aligned}
X & =\left[\begin{array}{llllll}
X_{1} & \dot{X}_{1} & X_{2} & \dot{X}_{2} & X_{3} & \dot{X}_{3}
\end{array}\right]^{T} \\
U & =\left[\begin{array}{ll}
F_{3}
\end{array}\right] \\
W & =\left[\begin{array}{ll}
X_{0} & \dot{X}_{0}
\end{array}\right]^{T}
\end{aligned}
$$

The performance index $\mathrm{J}$ picked in this study is:

$$
\mathrm{J}=\lim \frac{1}{2 T} \int_{0}^{T}\left\{\begin{array}{l}
\rho_{1}\left(\ddot{\mathrm{x}}_{2}\right)^{2}+\rho_{2}\left(\mathrm{x}_{2}-\mathrm{x}_{1}\right)^{2}+\rho_{3}\left(F_{d}\right)^{2}+\rho_{4}\left(\ddot{x}_{3}\right)^{2}+ \\
\rho_{5}\left(\mathrm{x}_{3}-\mathrm{x}_{1}\right)^{2}+\rho_{6} \mathrm{~F}_{3}^{2}
\end{array}\right\} \mathrm{dt}
$$

In the formula, $\rho_{1}$ refers to the weighting coefficient of vehicle's acceleration, $\rho_{2}$ refers to the weighting coefficient of suspension dynamic deflection; $\rho_{3}$ refers to the weighting coefficient of tire's dynamic load; $\rho_{4}$ refers to the weighting coefficient of in-wheel motor's vertical acceleration; $\rho_{5}$ refers to the weighting coefficient of in-wheel motor suspension dynamic deflection; $\rho_{6}$ refers to the weighting coefficient of control force. The standard quadratic form of formula (5) is:

$\mathrm{J}=\lim \frac{1}{2 T} \int_{0}^{T}\left\{\begin{array}{l}X^{T} Q X+U^{T} R U+W^{T} T W+2 X^{T} N U+ \\ 2 X^{T} H W+2 W^{T} M U\end{array}\right\} \mathrm{dt}$

In the formula: $Q$ refers to the weighting metric of the status variable; $R$ refers to the weighting metric of the control variable; $T$ refers to the weighting metric of the disturb vector outside; $N 、 H 、 M$ refers to the weighting metric of the cross term.

Suppose that variants of the status variable $X$ are measurable, the control force of the controller can be calculated according to optical control law:

$$
\left.U=-R^{-1}\left[\left(N^{T}+B^{T} P\right) x+M^{T} M\right]=-K x-R^{-1} M^{T} W\right]
$$

In the formula: $K$ refers to the state feedback gain matrix, $K=R^{-1}\left(N^{T}+B^{T} P\right) ; P$ is the modified value of Riccati equation. 
If the weighting coefficient values are: $\rho_{1}=1 \mathrm{e}-8 、 \rho_{2}=2.5 \mathrm{e}-18 、 \rho_{3}=1 、 \rho_{4}=1 \mathrm{e} 5$ 、 $\rho_{5}=4 \mathrm{e} 12 、 \rho_{6}=1$, we can calculate the optimum state feedback gain matrix of those four active suspensions through the Matlab function $[K, S, E]=L Q R(A, B, Q, R, N)$.

\section{Simulation analysis on different mounting structures of in-wheel motor}

Under the help of Matlab/Simulink software, the smoothness and stability simulation analysis were made upon these four structures: optimum control of active suspension for in-wheel motor, inactive suspension for in-wheel motor, in-wheel motor fixed joint to the wheel, and 1/4 sized of sample vehicle's vertical model. Simulations on uniform rectilinear motion at the speed of $70 \mathrm{~km} / \mathrm{h}$ on $\mathrm{C}$ segment road were made basing on GB/T 4970-1996 'Method of random input running test-Automotive ride comfort'; the vehicle acceleration, the vehicle suspension dynamic deflection, the relative dynamic load of tires, and simulating results on vertical acceleration of in-wheel motor were outputted by the methods of time domain and frequency domain separately. As shown in figure 3 .
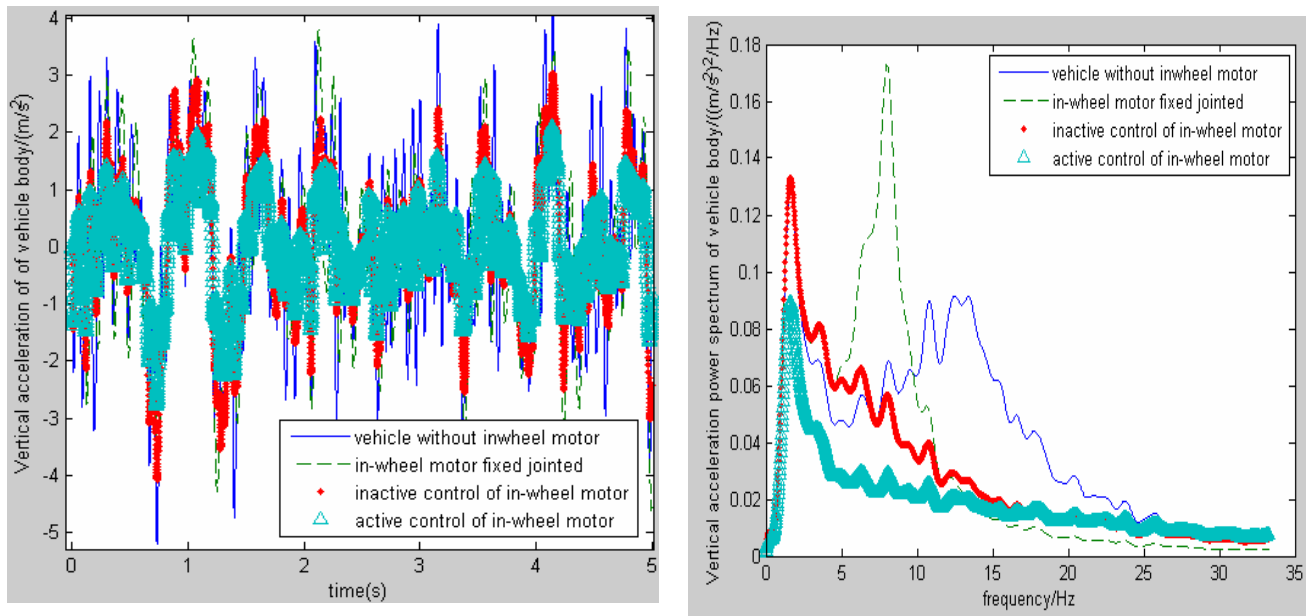

(a) Vehicle's vertical acceleration
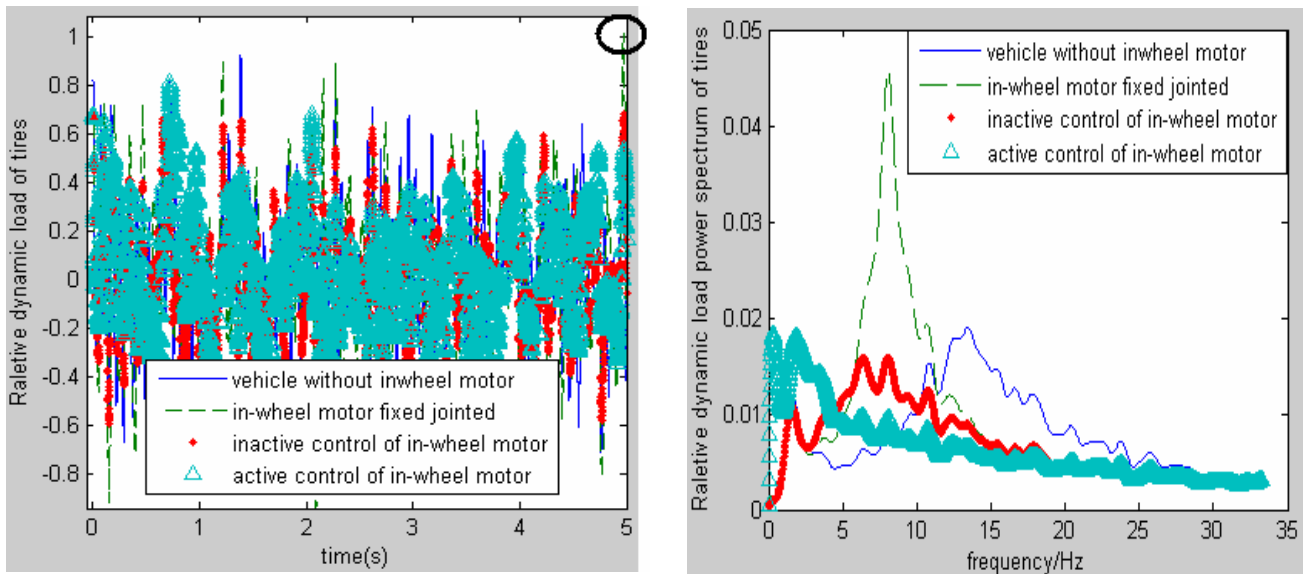

(b)Raletive dynamic load of tires 

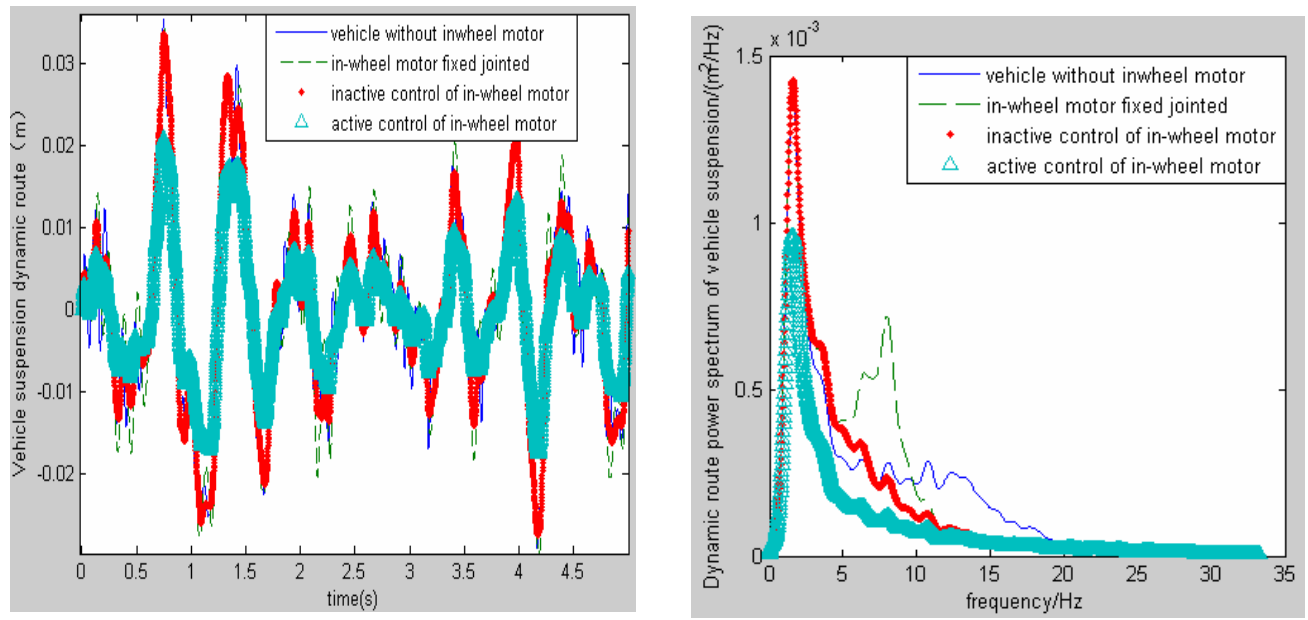

(c) Vehicle suspension dynamic route
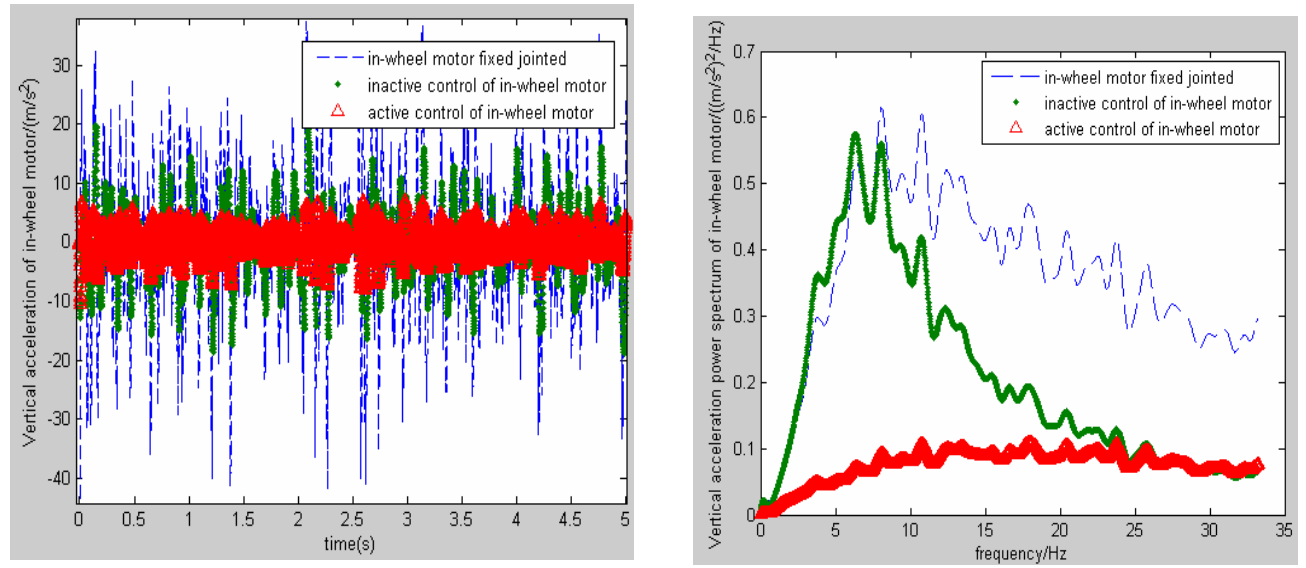

(d) Vertical acceleration of in-wheel motor

Fig. 3 Comparison of smoothness simulations about different models

The figure 3 above tells that, for in-wheel motor fixed jointed to the wheel, when the weight ratio of vehicle to wheels reduces, the power spectrum density property of vehicle acceleration, vehicle suspension dynamic route, and tire's dynamic load will move from high frequency resonance to low frequency, with peak value raise speedily. Figures 3(a) and (b) shows high frequency response can be decreased by changing in-wheel motor's mass into unsprung mass through the way of active/inactive control of in-wheel motor. In these figures, the thickest line representing in-wheel motor with active control suspension is in the range of the thin line for the sample vehicle. This means active suspension control for in-wheel motor can eliminate the negative vertical effect of fixed jointed motor; on the other hand, it can improve vehicle's smoothness and tire's protection. In figure 3(b), only fixed jointed in-wheel motor's relative dynamic load does not have the absolute value more than 1 (circled out), which proves that fixed jointed wheel may skip out of the ground, and in-wheel motor suspension is necessary and effective for road resistance.

In figure 3(c), fixed jointed in-wheel motor's vehicle suspension dynamic route make no difference from other models, and it's maximum suspension displace is among the ordinary vehicle, therefore, we needn't focus on this model. Figure 3(d) shows the control of active suspension for in-wheel motor can improve in-wheel motor's performance and stability when it's vertical acceleration decreased, compared to the control of inactive suspension for in-wheel motor. 


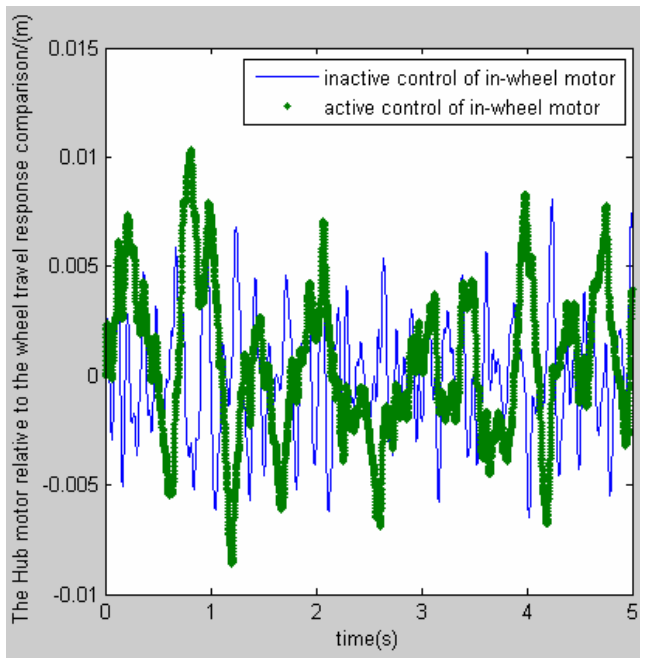

Fig. 4 The Hub motor relative to the wheel travel response comparison

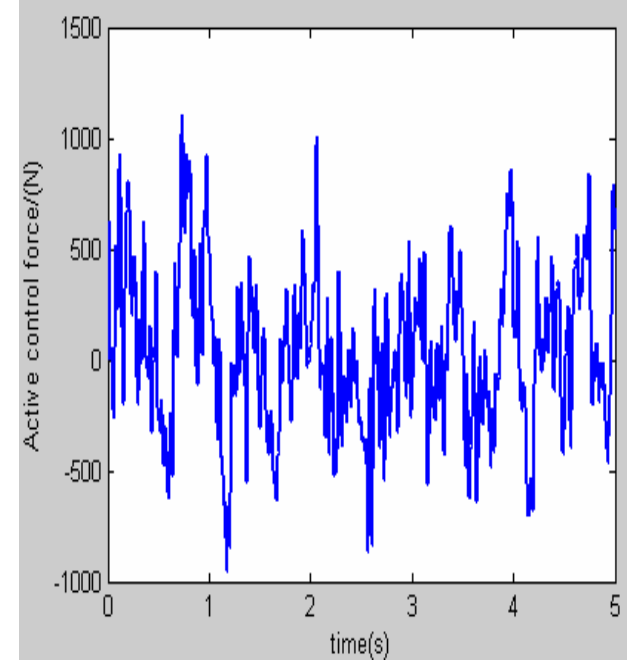

Fig. 5 Active control force

From figure 4, we can see the suspended in-wheel motor's dynamic route in the wheel is within $\pm 10 \mathrm{~mm}$, meeting the space request for 17 inch wheel rim and $10 \mathrm{KW}$ motor. In figure 5, the driving force is derived from the control of active suspension for in-wheel motor, with a maximum value of $1200 \mathrm{~N}$. Obviously, this force can satisfy the particle application for active actuator, which mainly works on the liner motor. To verify the results of the figures above, we compare different in-wheel motor models through the mean square value of the time domain simulation against different road and speed within 50s, as shown in the tables 2-4.

Table 2 Simulation results comparison of install hub motor different models at $\mathrm{C}$ level road and $100 \mathrm{~km} / \mathrm{h}$

\begin{tabular}{ccccc}
\hline mean square value & $\begin{array}{c}\text { Sample } \\
\text { cat }\end{array}$ & $\begin{array}{c}\text { Fixed } \\
\text { jointed }\end{array}$ & $\begin{array}{c}\text { Inactive } \\
\text { suspension }\end{array}$ & $\begin{array}{c}\text { Active } \\
\text { control }\end{array}$ \\
\hline Vehicle's vertical acceleration $\left(\mathrm{m} / \mathrm{s}^{\wedge}\right.$ 2) & 1.9570 & 2.0047 & 1.4176 & 0.8714 \\
Vehicle suspension dynamic route $(\mathrm{m})$ & 0.0101 & 0.0119 & 0.0101 & 0.0062 \\
Tire's relative dynamic load & 0.3739 & 0.4853 & 0.3118 & 0.2745 \\
In-wheel motor's vertical & -- & 16.8829 & 10.1536 & 3.5408 \\
acceleration $\left(\mathrm{m} / \mathrm{s}^{\wedge} 2\right)$ & & & & \\
\hline
\end{tabular}

Table 3 Simulation results comparison of install hub motor different models at $\mathrm{C}$ level road and $70 \mathrm{~km} / \mathrm{h}$

\begin{tabular}{ccccc}
\hline mean square value & $\begin{array}{c}\text { Sample } \\
\text { cat }\end{array}$ & $\begin{array}{c}\text { Fixed } \\
\text { jointed }\end{array}$ & $\begin{array}{c}\text { Inactive } \\
\text { suspension }\end{array}$ & $\begin{array}{c}\text { Active } \\
\text { control }\end{array}$ \\
\hline Vehicle's vertical acceleration $\left(\mathrm{m} / \mathrm{s}^{\wedge} 2\right)$ & 1.6548 & 1.7430 & 1.2714 & 0.7884 \\
Vehicle suspension dynamic route $(\mathrm{m})$ & 0.0099 & 0.0113 & 0.0100 & 0.0062 \\
Tire's relative dynamic load & 0.2971 & 0.4033 & 0.2529 & 0.2365 \\
In-wheel motor's vertical & -- & 12.9244 & 8.2231 & 2.6816 \\
acceleration $\left(\mathrm{m} / \mathrm{s}^{\wedge} 2\right)$ & & & & \\
\hline
\end{tabular}

Table 4 Simulation results comparison of install hub motor different models at B level road and $100 \mathrm{~km} / \mathrm{h}$

\begin{tabular}{ccccc}
\hline mean square value & Sample & Fixed & Inactive & Active \\
& cat & jointed & suspension & control \\
\hline
\end{tabular}




\begin{tabular}{ccccc}
\hline Vehicle's vertical acceleration $\left(\mathrm{m} / \mathrm{s}^{\wedge} 2\right)$ & 0.9522 & 0.9749 & 0.6896 & 0.4264 \\
Vehicle suspension dynamic route $(\mathrm{m})$ & 0.0049 & 0.0058 & 0.0049 & 0.0030 \\
Tire's relative dynamic load & 0.1829 & 0.2372 & 0.1509 & 0.1347 \\
In-wheel motor's vertical & -- & 8.3152 & 4.8870 & 1.7599 \\
acceleration $\left(\mathrm{m} / \mathrm{s}^{\wedge} 2\right)$ & & & & \\
\hline
\end{tabular}

Tables 2-4 tells that, compared to the sample car without in-wheel motor, in-wheel motor fixed jointed to the wheel causes the mean square value of vehicle acceleration, suspension's dynamic route and tire's relative dynamic load increase. This result corresponds to the area arounded by projector power spectral density curve, showed in figure 3. Meanwhile, the result tells that in-wheel motor will cause smoothness and earth resistance problems if the road uneven degree and frequency increases. With in-wheel motor mounted, the smoothness data against different roads is smaller than the fixed jointed motor. As the suspension parameter is optimized, the mean square values of vehicle acceleration and tire's relative dynamic load are smaller than the sample car. The mean square value of tire's relative dynamic load in the table shows that in-wheel motor can eliminate the possibility of vehicle skipping off the ground. For the control of active suspension for in-wheel motors, each indicator declines obviously, especially for the vertical accelerations of vehicle's suspension mass and in-wheel motor mass, these mummers decline more than $64 \%$, comparing to inactive suspension under the conditions above, improving the riding comfort, earth resistance and the motor's stability.

\section{Conclusions}

To sum up, join the in-wheel motor fixedly to the wheel can affect the vehicle's smoothness and the earth resistance, comparing to sample car. However, mounting the in-wheel motor through inactive suspension can eliminate those effection, and can benefit the vehicle in vehicle's acceleration and earth resistance. But, using optimum control suspension for in-wheel motor can not only work better than inactive suspension for in-wheel motor in lowering vehicle's vertical acceleration, vehicle suspension dynamic route and tire's relative dynamic load, but also obviously reducing the in-wheel motor's impact force on rough roads, making electric motor's design easier. Moreover, the control force of active suspension for in-wheel motor and the motor's route in the wheel are practical and feasible, which lays a foundation for applying the in-wheel motor driven electric cars.

\section{Acknowledgement}

The authors greatly appreciate the support provided by the China 863 project, project number 2012 AA 111803.

\section{References}

(1) H. C. Lovatt, V. S. Ramsden,B.C. Mecrow, Design of an in-wheel motor for a solar-powered electric vehicle. IEE Proc-electr Power Appl, Vol.145, No 5(1998), pp. 402-408.

(2) M. Shino, N. Miyamoto, Y. Q. Wang, M. Nagai Traction control of electric vehicles considering vehicle stability, Advanced Motion Control, No 6(2000), pp. 311-316.

(3) A. H. Niasar, H. Moghbeli, R. Kazemi, Yaw moment control via emotional adaptive neuro-fuzzy controller for independent rear wheel drives of an electric vehicle, IEEE Conference on Control Applications, Vol.1 (2003), pp. 380-385.

(4) K. Donghyun, H. Sungho, K. Hyusoo, Rear motor control for a 4 wd hybrid electric vehicle stability, IEEE International Conference on Vehicular Electronics and Safety, No 1 (2005), pp. 86-91.

(5) H. Sado, S. Sakai, Y. Hori, Road condition estimation for traction control in electric vehicle, Proceedings of the IEEE International Symposium on Industrial Electronics, Vol.2 (1999), pp. 973-978.

(6) R. Puscar, Y. Ait-Amirat, A. Berthon, J. M. Kauffmann, Modeling and simulation of a traction control algorithm for an electric vehicle with four separate wheel drives, IEEE Vehicular Technology Conference. Vol.3, No 56 (2001), pp. 1671-1675.

(7) M. Jalili-kharaajoo, F. Besharati, Sliding mode traction control of an electric vehicle with four separate wheel drives, IEEE Conference on Emerging Technologies and Factory Automation. Vol.2 (2003), pp. 291-296.

(8) G-B Ning, Wan Gang, The present research situation of the influences on vehicle vertical performance induced by direct wheel drives system, Automobile Technology, No 3 (2007), pp. 


\section{1-25(in Chinese).}

(9) C-L Xia, G-B Ning, Active control of vertical vibration negative influence induced by high unsprung mass of in-wheel motor electric vehicle, Chinese Journal of Construction Machinery, Vol. 4, No 1 (2006), pp. 31-42(in Chinese).

(10) X-P Zhang, G-B Ning, The present research situation of the influences on vehicle vertical performance induced by direct wheel drives system, Beijing Automotive Engineering, No 6 (2006), pp. 20-24(in Chinese).

(11) Z-S Yu, Theory of automobile, Bei jing: China Machine Press, 2009(in Chinese).

(12) A. G. Thompson, Design of active suspensions, Proceedings of the Institution of Mechanical Engineers, Vol. 185 (1970-1971), pp. 553-563.

(13) M. Yamashita, K. Fuinmori, K. Hayakawa, H. Kimura, Application of $\mathrm{H}_{\infty}$ control to active suspension systems, Automatic, Vol.3 ,No 11(1994), pp. 1717-1729.

(14) D. Karnopp, Active and semi-active vibration isolation, Transactions of the ASME, J. Mechanical Design, Vol.117 B (1995), pp. 177-185.

(15) L-Q Jin, C-X Song, Q-N Wang, Evaluation of Influence of Motorized Wheels on Contact Force and Comfort for Electric Vehicle, Journal of Computers, Vol. 6, No. 3(2011), pp. 497-505.

(16) Zhao Yan'E, J-W Zhang, X. Han, Design and Study on the Dynamic-damper Mechanism for an In-wheel Motor Individual Drive Electric Vehicle, Mechanical Science and Technology for Aerospace Engineering, Vol. 27,No 3(2008), pp. 395-404(in Chinese).

(17) X-Z Zhang, Vehicle control theory and Application, Bei jing: Chemical Industry Press, 2006(in Chinese). 